\title{
Retrospective review on: Local breast therapy in addition to systemic therapy in de-novo metastatic breast cancer
}

\author{
Tahani Nageeti ${ }^{1 *}$ and Raid Jastania ${ }^{2}$ \\ 1Jeddah Oncology Centre, King Abdullah Medical City -Holly Capital, Saudi Arabia \\ ${ }^{2}$ Department of Pathology, Umm AlQura University, Saudi Arabia
}

\begin{abstract}
To evaluate the impact of local therapies on survival and disease progression in patients presented with stage IV breast cancer who are treated with appropriate systemic therapy if local therapy done early on in the course of management. A retrospective cohort study of 61 females with de novo stage IV and received systemic therapy \pm local therapies. Thirty nine patients had local therapy (LT) (63.9\%) vs. 22 patients (36.1\%) had no-local therapy (no-LT). Median overall survival for total population was (40 months). Median OS in LT-group was 43 months Std. Error 3.86 (95\% CI: 35.43-50.57), vs. no- LT group was 26.0 months Std. Error 8.17 (95\% CI: 9.980-42.02), (log-rank test=2.492; 1 df; P=0.114). Median time to first progression (TTFP) for total population was (21 months, Std. Error 4.45 (95\% CI 12.27- 29.73). Median TTFP in LT-group was 26 months Std. Error 8 (95\% CI: 10.4-41.5), and no- LT group was 13 months Std. Error 4 (95\% CI: 5-20.9), (log-rank tes $=2.85 ; 1 \mathrm{df} ; \mathrm{P}=0.091$ ). Loco-regional therapy in de novo metastatic breast cancer has no impact on survival or time to first progression. Systemic therapy in this patient population remains the standard of care.
\end{abstract}

\section{Introduction}

Breast cancer is the most common malignancy among females. It accounts for $12.5 \%$ of all cancers. Saudi Arabian National Cancer Registry showed $26 \%$ of all cancer among females is breast cancers, and $12.8 \%$ are presented as stage-IV compared to $6 \%$ incidence in Surveillance Epidemiology and End Results database (SEER) [1,2]. The standard of care for patients with metastatic breast cancer is systemic treatment with palliative intent while local therapy has been reserved for palliation for cases with primary tumor complications, such as skin ulceration, infection and bleeding. Due to the advancement in breast cancer systemic treatment in the last decade a longer survival is observed even in stage IV patients that led to a greater interest for prophylactic local therapy to prevent devastating local progression. A number of retrospective and SEER data analysis suggests that local therapy in form of surgery or radiation of the primary breast tumor in patients with stage-IV disease at initial presentation might have a positive impact on survival [3-11]. Despite the trend in overall survival benefit in this group of patients treated with this approach, often patients selected were younger and presented with oligo- bony or soft tissue metastases [12]. They also had less co-morbidities compared to the non-surgical group presumably because surgeons were reluctant to expose patients with poor prognostic features to the risks of surgery. In one of the retrospective study, the benefit is only seen among patients operated on before diagnosis of metastatic disease and it is suggested as a consequence of stage migration bias [6]. Others found that surgery remains an independent factor associated with improvement on survival on a multivariate analysis [7]. Other retrospective study on local therapy in de novo metastatic breast cancer patients suggested a greater benefit was seen in patients who were eligible to have targeted therapy in form of anti-estrogenic drugs and Herceptin [13].

The biologic theories of the interactions between primary tumour and foci of metastasis are bidirectional. One theory suggests that local removal of disease might enhance the growth of metastasis because primary tumour was producing angiogenesis inhibitors and removal of primary tumor will induce angiogenesis [14-19]. On the other hand another theory on how local control may improve survival: hypothesis that controlling the disease locally reduces the overall tumor burden in addition to benefit of eliminating a potential source of metastatic spread and that loco-regional therapy eliminates the subset of cancer stem cells that are resistant to chemotherapy.

Multiple retrospective reviews examined the role of breast surgery $v s$. no surgery but very limited data on the survival advantage in using breast radiotherapy as solo local treatment or in combination with surgery in metastatic breast cancer. A recent publication on locoregional radiotherapy in patients with oligometastesis suggested that radiation alone has the same outcome on local control, progression free survival and overall survival as surgery plus radiotherapy [20]. The benefit of local therapy in patients presenting with metastatic breast cancer is not well established. We hypothesized that all forms of local therapies have survival benefit in patients with de novo stage IV breast cancer who are treated with appropriate systemic therapy if local therapy done early on in the course of management if we adjust for other potential cofactors.

\section{Material and methods}

Retrospective cohorts of women with metastatic breast cancer patients who present as de novo stage IV and received systemic

Correspondence to: Tahani Nageeti, MBChB, FRCPC, King Abdul-Aziz Medical City-Jeddah, King Saud Bin Abdul-Aziz University, Jeddah, PO . Box 7700, Makkah 24246, Saudi Arabia, Tel: 02-56650000; Fax: 02-5532235; E-mail: nageeti@hotmail.com/nageeti.t@kamc.med.sa

Key words: local breast therapy, de-novo metastatic, breast cancer

Received: April 03, 2015; Accepted: April 28, 2015; Published: May 02, 2015 
therapy. This retrospective research was approved by research hospital committee. Patient data were collected from patients whom were treated in Princess Norah Oncology Centre at King Abdul-Aziz Medical City in Jeddah from 2002-2008. Two institutional databases were searched to identify patients' population using two main keyword sets which are: (1) stage IV breast cancer (2) metastatic breast cancer.

\section{Inclusion criteria}

- $\quad$ Patient age $\geq 18$ year of age.

- Female breast cancer.

- $\quad$ Stage IV Invasive breast cancer

- Ductal or Lobular histology.

- Patient was fit to receive any form of systemic therapy either chemotherapy or hormonal therapy or other targeted therapy or combination.

\section{Exclusion criteria}

- Male patient.

- Patient age $<18$ year.

- Uncommon histology for breast cancer (lymphoma, sarcoma, phylloidus tumor, small cell tumor).

Of the 412 charts identified and reviewed only 61 patients (14.8\%) were eligible to our study. Patient charts and medical records were reviewed for the 61 patients. Patients data were retrieved and collected on: local therapy, surgery, radiation, patient age at diagnosis, date of diagnosis, menopausal status, site of metastasis, extent of metastasis, histology, tumor and nodal stage, oestrogen, progesterone and Her2 status, data on local therapy, systemic therapy, initial response to chemotherapy and second line chemotherapy.

Data on survival, and progression were obtained from patients' medical records and, in some cases through telephone calls.

The primary objective of this study was to evaluate the impact of local therapy (LT) on patient overall survival in months (OS) in de novo stage IV breast cancer. Overall survival was defined as interval from diagnosis until death of any cause or last follow-up. Secondary objectives were to evaluate the impact of LT on time-to first progression (TTFP) which was defined as the interval between diagnoses until clinical or radiological confirmation of first disease progression.

\section{Statistical analysis}

All statistical analysis was done using SPSS v.19. We performed the normality test on our data to insure it's normally distributed. Sample was grouped into two groups based on if patients received either local therapy (LT) or no local therapy (no-LT). Baseline characteristics of patients in both groups were compared using Fisher exact test for categorical variables and Student t-test for continuous variables when applicable. Kaplan-Meier method was used for calculation and plot of survival and TTFP curve of LT vs. no- LT patients groups, and the logrank test was used for the comparison of the survival curve. Statistically significant difference was considered when $\mathrm{P}$-values $<0.05$. To evaluate the independent contribution of each variable on survival, covariates significantly associated with survival $(\mathrm{P}<.05)$ in univariant analysis were included in a multivariate analysis. Cox-Regression model was used for multivariate analysis. Factors evaluated in the model included: surgical resection, radiation, patient age, menopausal status, site of metastasis, extent of metastasis, tumor stage , nodal stage, oestrogen receptor, progesterone receptor, Her-2 status, and initial response to chemotherapy

\section{Results}

Sixty-one patients were eligible, they met inclusion criteria and included in the analysis. Median age at diagnosis is 48 year $($ mean $=50.48)$. Total population characteristics are shown in Table 1. Postmenopausal women were $(45.9 \%)$ and premenopausal were

Table 1. Patients characteristics for total population.

\begin{tabular}{|c|c|c|c|c|}
\hline Category & Characteristics & $\begin{array}{l}\text { Frequency } \\
\text { (patients) }\end{array}$ & $\begin{array}{l}\text { Percent } \\
(\%)\end{array}$ & $\begin{array}{l}\text { Valid } \\
\text { Percent }\end{array}$ \\
\hline \multirow[t]{3}{*}{ Age category } & $=<60 \mathrm{y}$ & 45 & 73.8 & 73.8 \\
\hline & $>60 y$ & 16 & 26.2 & 26.2 \\
\hline & Total & 61 & 100 & 100 \\
\hline \multirow[t]{3}{*}{ Menopausal Status } & Premenopausal & 33 & 54.1 & 54.1 \\
\hline & Postmenopausal & 28 & 45.9 & 45.9 \\
\hline & Total & 61 & 100 & 100 \\
\hline \multirow[t]{4}{*}{ Metastatic site } & Bone or soft tissue only & 14 & 23 & 23 \\
\hline & Visceral & 44 & 72.1 & 72.1 \\
\hline & Brain & 3 & 4.9 & 4.9 \\
\hline & Total & 61 & 100 & 100 \\
\hline \multirow[t]{3}{*}{ Extent of Metastasis } & Multiple & 54 & 88.5 & 88.5 \\
\hline & Oligo & 7 & 11.5 & 11.5 \\
\hline & Total & 61 & 100 & 100 \\
\hline \multirow[t]{6}{*}{ T Stage } & $\mathrm{T} 1$ & 3 & 4.9 & 4.9 \\
\hline & $\mathrm{T} 2$ & 6 & 9.8 & 9.8 \\
\hline & $\mathrm{T} 3$ & 16 & 26.2 & 26.2 \\
\hline & $\mathrm{T} 4$ & 21 & 34.4 & 34.4 \\
\hline & Not Known & 15 & 24.6 & 24.6 \\
\hline & Total & 61 & 100 & 100 \\
\hline \multirow[t]{6}{*}{ N Stage } & N0 & 1 & 1.6 & 1.6 \\
\hline & N1 & 10 & 16.4 & 16.4 \\
\hline & $\mathrm{N} 2$ & 22 & 36.1 & 36.1 \\
\hline & N3 & 5 & 8.2 & 8.2 \\
\hline & Not Known & 23 & 37.7 & 37.7 \\
\hline & Total & 61 & 100 & 100 \\
\hline \multirow[t]{4}{*}{ Estrogen Receptors } & Positive & 39 & 63.9 & 63.9 \\
\hline & Negative & 13 & 21.3 & 21.3 \\
\hline & Not Known & 9 & 14.8 & 14.8 \\
\hline & Total & 61 & 100 & 100 \\
\hline \multirow[t]{4}{*}{ Progesterone Receptors } & Positive & 31 & 50.8 & 50.8 \\
\hline & Negative & 21 & 34.4 & 34.4 \\
\hline & Not Known & 9 & 14.8 & 14.8 \\
\hline & Total & 61 & 100 & 100 \\
\hline \multirow[t]{4}{*}{ Her-2 status } & Positive & 13 & 21.3 & 21.3 \\
\hline & Negative & 31 & 50.8 & 50.8 \\
\hline & Not Known & 17 & 27.9 & 27.9 \\
\hline & Total & 61 & 100 & 100 \\
\hline \multirow[t]{3}{*}{ Local Therapy } & No & 22 & 36.1 & 36.1 \\
\hline & Yes & 39 & 63.9 & 63.9 \\
\hline & Total & 61 & 100 & 100 \\
\hline \multirow[t]{3}{*}{ Surgery } & No & 25 & 41 & 41 \\
\hline & Yes & 36 & 59 & 59 \\
\hline & Total & 61 & 100 & 100 \\
\hline \multirow[t]{4}{*}{ Type of Surgery } & No Surgery & 25 & 41 & 41 \\
\hline & Lumpectomy & 11 & 18 & 18 \\
\hline & Mastectomy & 25 & 41 & 41 \\
\hline & Total & 61 & 100 & 100 \\
\hline
\end{tabular}




\begin{tabular}{|c|c|c|c|c|}
\hline \multirow[t]{3}{*}{ Radiation Therapy } & No & 49 & 80.3 & 80.3 \\
\hline & Yes & 12 & 19.7 & 19.7 \\
\hline & Total & 61 & 100 & 100 \\
\hline \multirow{4}{*}{$\begin{array}{l}\text { Type of Radiation } \\
\text { Therapy }\end{array}$} & Loco-Regional & 11 & 18 & 18 \\
\hline & Local & 1 & 1.6 & 1.6 \\
\hline & No Radiation & 49 & 80.3 & 80.3 \\
\hline & Total & 61 & 100 & 100 \\
\hline \multirow[t]{5}{*}{ Radiation Dose in cGY } & 4240 & 1 & 1.6 & 8.3 \\
\hline & 5000 & 8 & 13.1 & 66.7 \\
\hline & 6000 & 2 & 3.3 & 16.7 \\
\hline & 6600 & 1 & 1.6 & 8.3 \\
\hline & Total & 12 & 19.7 & 100 \\
\hline \multirow[t]{3}{*}{ Hormonal Therapy } & No & 24 & 39.3 & 39.3 \\
\hline & Yes & 37 & 60.7 & 60.7 \\
\hline & Total & 61 & 100 & 100 \\
\hline \multirow[t]{3}{*}{ Initial Chemotherapy } & No & 13 & 21.3 & 21.3 \\
\hline & Yes & 48 & 78.7 & 78.7 \\
\hline & Total & 61 & 100 & 100 \\
\hline \multirow{6}{*}{$\begin{array}{l}\text { Response to Systemic } \\
\text { Therapy }\end{array}$} & Partial & 27 & 44.3 & 44.3 \\
\hline & Complete & 16 & 26.2 & 26.2 \\
\hline & Stable & 12 & 19.7 & 19.7 \\
\hline & Progression & 5 & 8.2 & 8.2 \\
\hline & Not Assessed & 1 & 1.6 & 1.6 \\
\hline & Total & 61 & 100 & 100 \\
\hline \multirow{3}{*}{$\begin{array}{l}\text { Second Line } \\
\text { Chemotherapy }\end{array}$} & No & 33 & 54.1 & 54.1 \\
\hline & Yes & 28 & 45.9 & 45.9 \\
\hline & Total & 61 & 100 & 100 \\
\hline
\end{tabular}

(54.1\%). Oestrogen receptors positive disease were found in $(63 \%)$ of our patients, progesterone receptors positive in $(54.1 \%)$ and her2 positive in $(21.3 \%)$. Eighty-eight percent of our patients presented with multiple metastases and most presented with visceral metastasis (72.1\%), while bony metastasis in $(23 \%)$ and brain metastasis (4.9\%). All patients received a variety of systemic therapy either of Chemotherapy only (24 patients) or targeted therapy (13 patients) or both (24 patients).

Of the 61 patients 39 had LT (63.9\%) vs. 22 patients (36.1\%) had no-LT. of the 39 patients who had local therapy: 27 patients had surgery only, 3 patients had radiation only and 9 patients had both surgery and radiation. Eleven patients (18\%) had lumpectomy, 25 patients $(41 \%)$ underwent for mastectomy. Twelve patients had radiation $(19.7 \%)$, only one patient had local radiotherapy (1.6\%), while the other 11 patients (18\%) had loco-regional radiation with dose range from (4240-6600cGY).

Patients' characteristics for the two treatment groups are shown in Table 2. Characteristics were similar in the two groups, except there were more patients with higher nodal stage $(\mathrm{N} 2, \mathrm{~N} 3)$ in the local therapy group (0.019).

Overall survival in months for total population was (40 months, Std. Error 3.84 (95\% CI 32.471-47.529). Median OS in LT-group was 43 months Std. Error 3.86 (95\% CI: 35.43-50.57), vs. no- LT group was 26.0 months Std. Error 8.17 (95\% CI: 9.980-42.020), (log-rank test $=2.492 ; 1$ df; $\mathrm{P}=0.114$ ) (Figure 1).

Time to first progression for total population was (21 months, Std. Error 4.45 (95\% CI 12.27- 29.73). TTFP in LT-group was 26 months Std. Error 8 (95\% CI: 10.4-41.5), and no- LT group was 13 months Std. Error 4 (95\% CI: 5-20.9), (log-rank test=2.85; 1 df; $\mathrm{P}=0.091)$.

On univariate and subsequent multivariate analyses of predictive factors we found only progesterone receptor positivity remains an independent prognostic factor for improved overall survival $(\mathrm{p}<0.028)$. Progesterone receptor positive $(\mathrm{P}=0.039)$ and use of radiotherapy $(\mathrm{p}=0.001)$ remains independent prognostic factors for improved TTFP.

\section{Discussion}

Standard of care for patient presented with metastatic breast cancer is palliative systemic therapy. The optimal management in this group of patient is not well defined, as many retrospective data suggest that local therapy might improve survival [8]. None of the publish results were prospective study, selection bias was considered a major issue as patients who offer this type of treatment were tend to be younger, fitter and have less disease burden. Indications of local therapy were: primary surgery while metastasis is discovered later at time of staging, palliation of local symptoms to avoid uncontrolled chest wall disease and in some cases as curative treatment for patients with controlled metastatic disease. Local therapy was either given in form of surgery alone, radiation alone or combination of both. Therapies were either given local or more comprehensive of loco-regional and some are more of palliative.

Our study showed there is no difference in overall survival or progression free survival between patients who received local therapy in any form and patient who did not receive any local therapy if the patient received appropriate systemic therapy. All of our patients received systemic therapy which represent the modern era where appropriate hormonal and other targeted therapies are offered for most of those group of patient. In our study we found that the presence of progesterone receptor positivity is an independent factor associated with improved survival and time to first failure. This suggests that the presence of effective systemic targeted therapy associated with improved outcome.

In multivariate analysis of our data we found that radiation associated with improved TTFP and we observed that all of our patients had radical dose of radiotherapy and all had loco-regional radiation except one had local therapy only. In addition some of published data showed

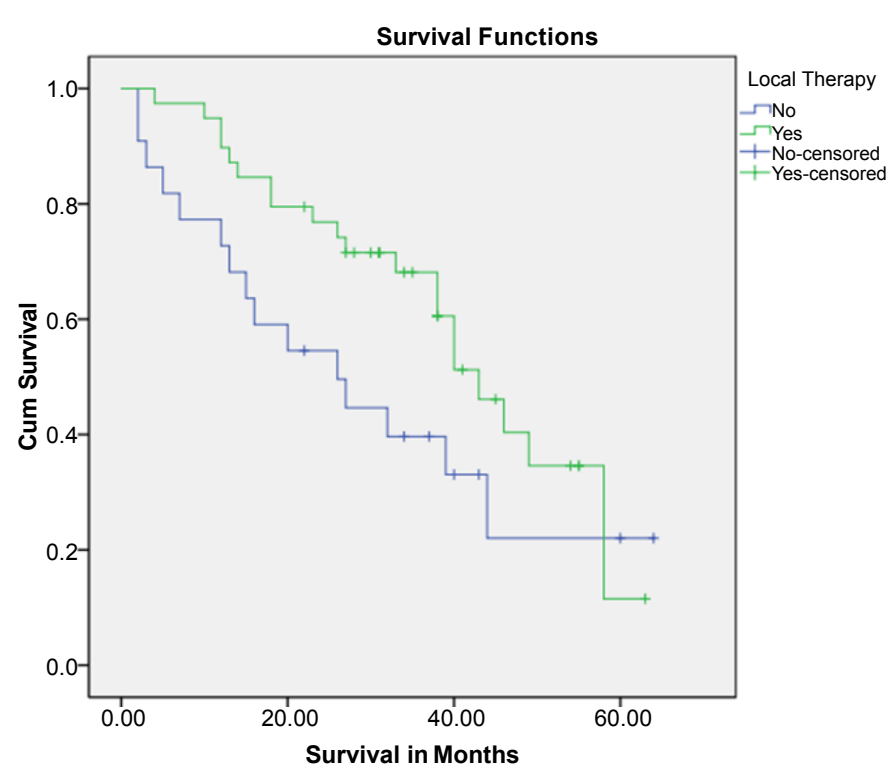

Figure 1. Kaplan-Meier Survival Curve for the two groups: group one had no local therapy (no-LT) and group two had local therapy (LT). 
Table 2. Shows patients characteristics for the two treatment groups.

\begin{tabular}{|c|c|c|c|c|c|}
\hline & & \multicolumn{2}{|c|}{ Local Therapy } & \multirow{3}{*}{\begin{tabular}{c|} 
Total \\
61 \\
\end{tabular}} & \multirow{3}{*}{\begin{tabular}{|c|} 
P-Value \\
0.18 \\
\end{tabular}} \\
\hline & & \multirow{2}{*}{$\begin{array}{c}\text { LT } \\
\mathrm{N}=39 \\
\text { Mean }=48.31\end{array}$} & \multirow{2}{*}{$\begin{array}{c}\text { No- LT } \\
\mathrm{N}=22 \\
\text { Mean }=54.32\end{array}$} & & \\
\hline Patient Age & & & & & \\
\hline Menopausal Status & $\begin{array}{l}\text { Premenopausal } \\
\text { Postmenopausal }\end{array}$ & $\begin{array}{l}23 \\
16\end{array}$ & $\begin{array}{l}10 \\
12\end{array}$ & $\begin{array}{l}33 \\
28\end{array}$ & 0.4 \\
\hline Extent of Metastasis & $\begin{array}{l}\text { Oligo } \\
\text { Multiple }\end{array}$ & $\begin{array}{c}34 \\
5\end{array}$ & $\begin{array}{c}20 \\
2\end{array}$ & $\begin{array}{c}54 \\
7\end{array}$ & 0.9 \\
\hline Site of Metastasis & $\begin{array}{l}\text { Bone/Soft Tissue } \\
\text { Vesiral/Brain }\end{array}$ & $\begin{array}{c}9 \\
30\end{array}$ & $\begin{array}{c}5 \\
17\end{array}$ & $\begin{array}{l}14 \\
47\end{array}$ & 1 \\
\hline Tumor Stage & $\begin{array}{l}\text { T1, T2 } \\
\text { T3, T4 }\end{array}$ & $\begin{array}{c}8 \\
24\end{array}$ & $\begin{array}{c}1 \\
13\end{array}$ & $\begin{array}{c}9 \\
37\end{array}$ & 0.24 \\
\hline Nodal Stage & $\begin{array}{l}\mathrm{N} 0, \mathrm{~N} 1 \\
\mathrm{~N} 2, \mathrm{~N} 3\end{array}$ & $\begin{array}{c}5 \\
23\end{array}$ & $\begin{array}{l}6 \\
4\end{array}$ & $\begin{array}{l}11 \\
27\end{array}$ & 0.019 \\
\hline Her-2 status & $\begin{array}{l}\text { Positive } \\
\text { Negative/Unknown }\end{array}$ & $\begin{array}{l}10 \\
29\end{array}$ & $\begin{array}{c}3 \\
19\end{array}$ & $\begin{array}{l}13 \\
48\end{array}$ & 0.22 \\
\hline Estrogen Receptor & $\begin{array}{l}\text { Positive } \\
\text { Negative/Unknown }\end{array}$ & $\begin{array}{l}24 \\
15\end{array}$ & $\begin{array}{c}15 \\
7\end{array}$ & $\begin{array}{l}39 \\
22\end{array}$ & 0.78 \\
\hline Progesterone Receptor & $\begin{array}{l}\text { Positive } \\
\text { Negative/Unknown }\end{array}$ & $\begin{array}{l}19 \\
20\end{array}$ & $\begin{array}{l}12 \\
10\end{array}$ & $\begin{array}{l}31 \\
30\end{array}$ & 0.79 \\
\hline
\end{tabular}

an association of free surgical resection margin and improvement of survival [8], all these raised the issue of the quality of local therapies that offered in this sitting, and it give us more suggestion that the question of loco-regional therapy in patient with de novo metastasis breast cancer should be addressed in randomized controlled trial with elimination of all bias and provide full control on the quality of locoregional therapy that offer to patients. As may be more comprehensive loco-regional therapy will be translated into improved local control and prolonged survival. Currently a few randomized controlled studies addressing this question are conducted by: TATA Memorial Hospital in India, Turkish Federation of Breast Cancer Societies and the Eastern Cooperative Oncology Group (ECOG Trial E2108). All addressing the issue of adding local therapy to appropriate chemotherapy in de novo metastatic breast cancer patients.

\section{Conclusion}

Loco-regional therapy in de novo metastatic breast cancer has no impact on survival. Systemic therapy is the mainstay of treatment. Intent of treatment should be palliative to improve quality of life. Local surgery and/or radiotherapy prior or immediately following palliative chemotherapy should not be considered as standard practice, should not replace systemic therapy and left to an individual patient benefit assessment.

\section{References}

1. Saudi Cancer Report, 2007.

2. Howlader N, Noone AM, Krapcho M, Neyman N, Aminou R, et al. (2012) SEER Cancer Statistics Review, 1975-2009 (Vintage 2009 Populations). National Cancer Institute. [http://seer.cancer.gov/archive/csr/1975_2009_pops09/]

3. Ruiterkamp J, Ernst MF, van de Poll-Franse LV, Bosscha K, Tjan-Heijnen VC, et al. (2009) Surgical resection of the primary tumour is associated with improved survival in patients with distant metastatic breast cancer at diagnosis. Eur J Surg Oncol 35: 1146-1151. [Crossref]

4. Ly BH, Nguyen NP, Vinh-Hung V, Rapiti E, Vlastos G (2010) Loco-regional treatment in metastatic breast cancer patients: is there a survival benefit? Breast Cancer Res Treat 119: 537-545. [Crossref]

5. McGuire KP, Eisen S, Rodriguez A, Meade T, Cox CE, et al. (2009) Factors associated with improved outcome after surgery in metastatic breast cancer patients. Am J Surg 198: 511-515. [Crossref]

6. Bafford AC, Burstein HJ, Barkley CR, Smith BL, Lipsitz S, et al. (2009) Breast surgery in stage IV breast cancer: impact of staging and patient selection on overall survival. Breast Cancer Res Treat 115: 7-12. [Crossref]

7. Blanchard DK, Shetty PB, Hilsenbeck SG, Elledge RM (2008) Association of surgery with improved survival in stage IV breast cancer patients. Ann Surg 247: 732-738. [Crossref]

8. Hazard HW, Gorla SR, Scholtens D, Kiel K, Gradishar WJ, et al. (2008) Surgical resection of the primary tumor, chest wall control, and survival in women with metastatic breast cancer. Cancer 113: 2011-2019. [Crossref]

9. Shien T, Kinoshita T, Shimizu C, Hojo T, Taira N, et al. (2009) Primary tumor resection improves the survival of younger patients with metastatic breast cancer. Oncol Rep 21: 827-832. [Crossref]

10. Gnerlich J, Jeffe DB, Deshpande AD, Beers C, Zander C, et al. (2007) Surgical removal of the primary tumor increases overall survival in patients with metastatic breast cancer: analysis of the 1988-2003 SEER data. Ann Surg Oncol 14: 2187-2194. [Crossref]

11. Fields RC, Donna BJ, Trinkaus K, Zhang Q, Arthur C, et al. (2007) Surgical resection of the primary tumor is associated with increased long-term survival in patients with stage IV breast cancer after controlling for site of metastasis. Ann Surg Oncol 14: 33453351. [Crossref]

12. Cady B, Nathan NR, Michaelson JS, Golshan M, Smith BL (2008) Matched pair analyses of stage IV breast cancer with or without resection of primary breast site. Ann Surg Oncol 15: 3384-3395. [Crossref]

13. Neuman HB, Morrogh M, Gonen M, Van Zee KJ, Morrow M, et al. (2010) Stage IV breast cancer in the era of targeted therapy: does surgery of the primary tumor matter? Cancer 116: 1226-1233. [Crossref]

14. Goldfarb Y, Ben-Eliyahu S (2006) Surgery as a risk factor for breast cancer recurrence and metastasis: mediating mechanisms and clinical prophylactic approaches. Breast Dis 26: 99-114. [Crossref]

15. Baum M, Demicheli R, Hrushesky W, Retsky M (2005) Does surgery unfavourably perturb the natural history of early breast cancer by accelerating the appearance of distant metastases? Eur J Cancer 41: 508-515. [Crossref]

16. Retsky M, Bonadonna G, Demicheli R (2004) Hypothesis: induced angiogenesis after surgery in premenopausal node-positive breast cancer patients is a major underlying reason why adjuvant chemotherapy works particularly well for those patients. Breast Cancer Res 6: R372-R384. [Crossref]

17. Fisher B, Gunduz N, Saffer EA (1983) Influence of the interval between primary tumor removal and chemotherapy on kinetics and growth of metastases. Cancer Res 43: 14881492. [Crossref]

18. Greenberg PA, Hortobagyi GN, Smith TL, Ziegler LD, Frye DK, et al. (1996) Long-term follow-up of patients with complete remission following combination chemotherapy for metastatic breast cancer. J Clin Oncol 14: 2197-2205. [Crossref] 
Nageeti T (2015) Retrospective review on: Local breast therapy in addition to systemic therapy in de-novo metastatic breast cancer

19. Demicheli R, Retsky MW, Swartzendruber DE, Bonadonna G (1997) Proposal for a new model of breast cancer metastatic development. Ann Oncol 8: 1075-1080. [Crossref]
20. Bourgier C, Khodari W, Vataire AL, Pessoa EL, Dunant A, et al. (2010) Breast radiotherapy as part of loco-regional treatments in stage IV breast cancer patients with oligometastatic disease. Radiother Oncol 96: 199-203. [Crossref]

Copyright: (C) 2015 Nageeti T. This is an open-access article distributed under the terms of the Creative Commons Attribution License, which permits unrestricted use, distribution, and reproduction in any medium, provided the original author and source are credited. 